\title{
Evaluating Water Miscible Deep Eutectic Solvents (DESs) and Ionic Liquids as Potential Lubricants
}

\author{
Andrew P. Abbott, ${ }^{a}$ Essa I. Ahmed, ${ }^{\mathrm{a}, \mathrm{b}}$ Robert C. Harris ${ }^{\mathrm{a}}$ and Karl S. Ryder ${ }^{\mathrm{a}}$ \\ ${ }^{a}$ Chemistry Department University of Leicester, Leicester, LE1 7RH, UK \\ ${ }^{b}$ Chemistry Department, Salahaddin University, Hawler, Iraq
}

\begin{abstract}
Although mineral oils are commonly used as lubricants their emission particularly in marine environments can cause significant impact. In the current study the properties of water miscible Deep Eutectic Solvents and ionic liquids are compared with a typical mineral base oil to ascertain their efficacy for potential marine lubricants. The environmental compatibility of some of the liquids, particularly choline chloride and glycerol, makes it an interesting potential base lubricant. Surprisingly some DESs showed very low corrosion rates with steel, nickel and aluminium even when the liquids contained water. This is a surprising result given that the chloride ion concentration is approximately $5 \mathrm{~mol} \mathrm{dm}^{-3}$.
\end{abstract}

Key words: ionic liquid, lubricant, corrosion, viscosity index, contact angle. 


\section{Introduction}

Lubricants are ubiquitous and perform a variety of functions such as cooling of surfaces, avoidance of corrosion, power transfer, offering a liquid seal at sliding contacts in addition to removal and suspension of wear products. Generally lubricating oils are formulated from a mixture of two or more base stocks (mineral oil, bio-based oil or synthetic oil) together with a variety of additives. ${ }^{1}$ Most common additives which are used in lubrication are intended to perform several roles, some of them are used to protect the surface of sliding solids, while other are aimed to enhance the performance of the lubricant itself and others are used to maintain the lubricant's properties. Examples of common additives include dispersants, antioxidants, friction modifiers, anti-wear agents, detergents and viscosity index improvers. ${ }^{2}$ While they generally have low toxicity on a small scale emission at sea in particular has significant environmental consequences. An additional issue for marine lubricants is the enhanced corrosion resulting from the incorporation of sea water in mineral oil based systems. ${ }^{3}$

Nowadays, the development of new products from renewable bio-based materials has become an important potential in the area of lubricant manufacturing. Triglycerides derivatives from seed oils are valued as important alternatives to conventional petroleum based base stocks as they are sustainable, generally environmentally compatible, nontoxic, biodegradable as well as small changes in viscosity as a function of temperature. Additionally, they are able to adhere to the metal surface giving them a great boundary lubrication role. Moreover, vegetable oils are readily able to dissolve additives and polar contaminants. However, their drawbacks are associated with their high sensitivity to oxidation, hydrolysis and high pour points. ${ }^{4,5}$ There are, however several polyalkylene glycol based water miscible lubricants which are also available although they have tended to be used for specialist applications. ${ }^{6}$

While most lubricants are non-polar and have low surface tension there have recently been a significant number of publications using ionic liquids as lubricants. ${ }^{7}$ It has been shown that these neoteric liquids have viscosity indexes which are superior to many mineral base oils and comparable to many semi-synthetic base oils. They have also been studied as additives for a range of base fluids particularly where the ionic liquids have surfactant properties. Under extreme wear conditions some ionic liquids can break down to produce tribofilms which protect the surface. Naturally there are some environmental issues with selected ionic liquids and the complex synthesis means that the cost of production limits their 
use to small volume specialised applications. The numerous combinations of cations and anions allow the physical and mechanical properties to be tailored for the application. Their wide liquid range, lack of flammability, high thermal stability and non-volatility makes them interesting candidates as lubricants. ${ }^{8}$ Most of the studies have been carried out using imidazolium, $\mathrm{BF}_{4}^{-}$and $\mathrm{PF}_{6}^{-}$due to their availability although other cations and anions are now being studied.

In an alternative approach we have previously demonstrated that eutectic mixtures of quaternary ammonium salts and hydrogen bond donors form liquids with properties similar to ionic liquids. ${ }^{9,10}$ These so-called deep eutectic solvents (DESs) have physical properties which would make them useful as lubricants. The base lubricant needs to have specific properties, including high viscosity index (VI), good friction coefficient reduction $(\mu)$, low pour point and low corrosivity. In this study deep eutectic solvents are compared with other water soluble ionic liquids and a mineral base oil and it is shown that the ionic fluids have enhanced thermophysical properties, corrosion resistance and wear resistance. ${ }^{1-3}$ It is interesting to note that while the hydrophobic oil and hydrophilic ionic liquids have similar molar masses the relative intermolecular or interionic forces are very different. While mineral oils are good at wetting hydrophobic metal surfaces such as aluminium we show that ionic liquids and DESs show improved wear characteristics with iron based alloys.

\section{Experimental}

The DESs were made by the method reported in the literature. ${ }^{9,10}$ The ionic liquids listed in Table 1 were used as received from BASF. Mobil Therm 605 was used as a standard heavy paraffinic petroleum distillate, solvent-dewaxed mineral base oil. The viscosity of all DESs was measured using both Ubbelohde and rotational (Brookfield DV-II+ Pro) viscometers. For rotating viscometer the spindle was rotated in each liquid between 5 and 200 rpm to ensure the appropriate torque and the resultant dynamic viscosities have been converted to kinematic viscosity using their densities at the same temperature.

Both density and surface tension were measured with a Krüss Tensiometer K9 model K9MK1. A liquid sample was placed in a glass dish surrounded by a water jacket. The temperature was controlled by a thermostat connected to the jacket. Surface tension measurement was recorded using a Pt-Ir alloy plate (Krüss, part number PL01). Contact angle measurements were performed using CAM 100 contact-angle meter from (Edmund industrial 
optics). Droplets of base oil, DESs and ILs have been formed at the end of a needle and brought into contact with specimen surfaces.

The corrosion studies were carried out using AUTOLAB instruments (Autolab PGSTAT12 and FRA2 $\mu$ AUTOLAB Type $ш$ ). In all experiments the metal samples (Al, Fe and Ni) were used as a working electrode and Pt electrode as a counter electrode however, the reference electrode used was $(\mathrm{Ag} / \mathrm{AgCl}$ in $1 \mathrm{M} \mathrm{KCl}$ concentration). The working electrodes used were made as disc electrodes for both $\mathrm{Fe}$ and $\mathrm{Al}$ and $\mathrm{Pt}$ electrode was made as a ring. For corrosion rate measurements using a.c. impedance the electrodes were polished initially with alumina $(0.05 \mu \mathrm{m})$ and then left in liquids at open circuit potential for between 1 and 48 hours without polishing. Corrosion rates were calculated using ASTM G 59-97

$\mathrm{i}_{\text {corr }}=\frac{1}{\left(2.3 \mathrm{R}_{\mathrm{p}}\right)}\left(\frac{\beta_{\mathrm{a}} \beta_{\mathrm{c}}}{\beta_{\mathrm{a}}+\beta_{\mathrm{c}}}\right)=\frac{B}{\mathrm{R}_{\mathrm{p}}}$

Where $\mathrm{i}_{\text {corr }}$ is the corrosion current density, $B$ is the Stern-Geary constant and Rp is the polarisation resistance. The value of icorr was obtained automatically from software and converted to corrosion rates by inserting equivalent weights and density values of each element in LSV and adjusted to electrode surface area $\left(\mathrm{cm}^{2}\right)$. For electrochemical impedance spectroscopy, EIS, values of $\left(\mathrm{R}_{\mathrm{P}}\right)$ have been derived from semi-circular Nyquist plots and converted to $i_{\text {corr. }}$ using following equation

$\mathrm{i}_{\text {corr. }}\left(\mu \mathrm{A} / \mathrm{cm}^{2}\right)=10^{6} \mathrm{~B} / \mathrm{Rp}$

Then, values are converted to corrosion rates in $\mathrm{mm} / \mathrm{year}$ from this equation

$\mathrm{CR}=3.27 \times 10^{-3} * \frac{\mathrm{i}_{\text {corr }} \mathrm{EW}}{\rho}$

Where $\mathrm{CR}$ is the corrosion rate in $\mathrm{mm} / \mathrm{year}, \mathrm{EW}$ is the equivalent weight $(\mathrm{g} / \mathrm{mole})$ and $\rho$ is the density of corroding sample $\mathrm{g} \mathrm{cm}^{-3}$

Friction coefficient data were determined using the standard pin on disc technique using a Teer Coatings ST-200 wear tester. In all cases the friction coefficient - time profile remained flat over (2000 cycles) and 1 hour at $0.005 \mathrm{~ms}^{-1}$ under load of $30 \mathrm{~N}$ at $293 \pm 1 \mathrm{~K}$. 


\section{Results and Discussion}

Thermophysical Data: To be suitable as lubricants fluids need to retain an appropriate viscosity profile over a wide range of temperature. This is generally expressed through the viscosity index (VI) which is defined as;

$$
\boldsymbol{V I}=100(\boldsymbol{L}-\boldsymbol{U}) /(\boldsymbol{L}-\boldsymbol{H})
$$

Where $\boldsymbol{U}$ is the kinematic viscosity at $40^{\circ} \mathrm{C}$ of the unknown oil; $\boldsymbol{L}$ is the kinematic viscosity at $40{ }^{\circ} \mathrm{C}$ of an oil $(\boldsymbol{V I}=0)$ having the same viscosity at $100^{\circ} \mathrm{C}$ as the unknown oil; $\boldsymbol{H}$ is the kinematic viscosity at $40{ }^{\circ} \mathrm{C}$ of an oil $(\boldsymbol{V I}=100)$ having the same viscosity at $100{ }^{\circ} \mathrm{C}$ as the unknown oil. ${ }^{11}$

It has previously been shown that the addition of quaternary ammonium salts lead to a decrease in the friction coefficient of fluids and the minimum friction occurs at the eutectic composition. ${ }^{12}$ In the current study four DESs were tested at their eutectic composition using choline chloride as the quaternary ammonium salt together with different hydrogen bond donors. These are compared with four water-miscible, imidazolium-based ionic liquids as shown in Table 1.

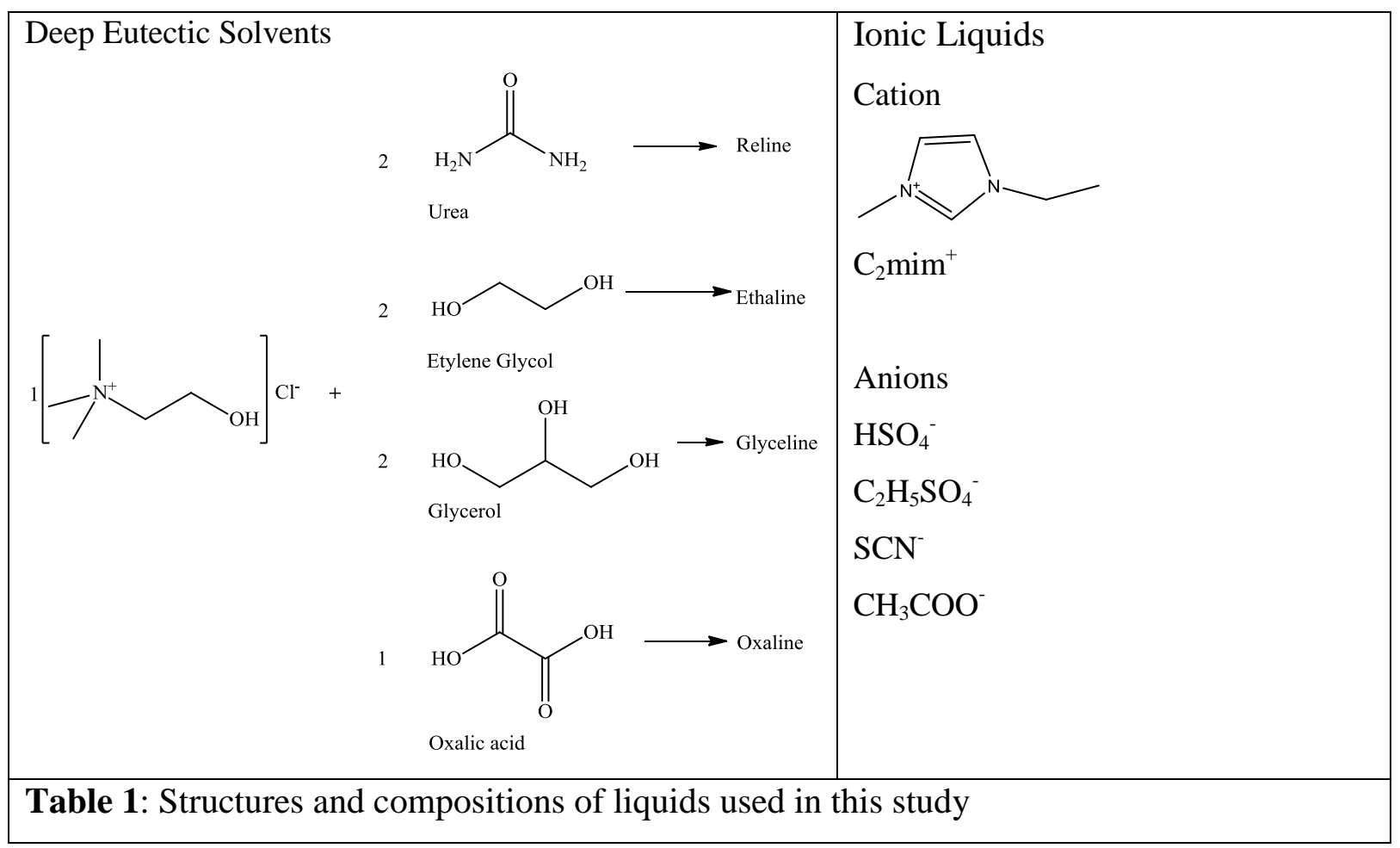


Table 2 shows thermo-physical and corrosion data for four DESs, four ionic liquids and a standard mineral base oil. It should be highlighted that this study is comparing the properties of the ionic fluids to those of the base lubricating fluid. The properties of finished lubricating fluids are usually superior to those in Table $\mathbf{2}$ due to complex additive packages.

The viscosity index is usually calculated using a U-tube viscometer to measure the kinematic viscosity. This method is only valid for truly Newtonian fluids where the viscous stress is proportional to the local shear rate. It is known that some ionic liquids have some non-Newtonian character. ${ }^{13}$ Most liquids in Table 2 showed Newtonian behaviour and good correlation was observed between the viscosity obtained from the Ubbelohde and rotating cylinder techniques. Reline and Oxaline showed non-Newtonian behaviour and so to give comparable results the average viscosity at a series of rotation rates was calculated. It should therefore be stressed that the VI data in Table 2 are comparative for some of the DESs. The viscosity indexes of the DESs and ionic liquids are higher in all cases to the base oil. All four DESs have viscosity indexes which are above the value of the base oil. It should be stressed however, than none of these liquids have additive packages added which would be used in the finished lubricant.

\begin{tabular}{|c|c|c|c|c|c|c|c|c|}
\hline \multirow{2}{*}{ Fluid } & \multicolumn{2}{|c|}{$\begin{array}{l}\text { Viscosity } \\
/ \mathrm{mm}^{2} \mathrm{~s}^{-1}\end{array}$} & \multirow{2}{*}{$\begin{array}{l}\text { Density } \\
\text { at } 25^{\circ} \mathrm{C} \\
/ \mathrm{g} \mathrm{cm}^{-3}\end{array}$} & \multirow[t]{2}{*}{$V I$} & \multirow[t]{2}{*}{$\begin{array}{c}\boldsymbol{T}_{f} \\
/{ }^{\circ} \mathrm{C}\end{array}$} & \multirow[t]{2}{*}{$\begin{array}{l}\text { Surface } \\
\text { tension } \\
/ \mathrm{mNm}^{-1}\end{array}$} & \multicolumn{2}{|c|}{$\begin{array}{c}\text { Corrosion of mild } \\
\text { steel } \\
/ \mu \mathrm{m}^{-1} \text { year }^{-1}\end{array}$} \\
\hline & $\begin{array}{c}\text { at } \\
40^{\circ} \mathrm{C}\end{array}$ & $\begin{array}{c}\text { at } \\
100^{\circ} \mathrm{C}\end{array}$ & & & & & LSV & EIS \\
\hline Base oil & 30 & 5 & 0.87 & 100 & -9 & 30.6 & ---- & ---- \\
\hline Ethaline & 20 & 5 & 1.12 & 191 & -61 & 49.2 & 1.9 & 5.02 \\
\hline Glyceline & 118 & 23 & 1.19 & 147 & -35 & 55.4 & 0.4 & 2.2 \\
\hline Reline & 218 & 24 & 1.20 & 121 & 12 & 86.4 & 2.5 & 2.7 \\
\hline Oxaline & 149 & 28 & 1.20 & 144 & -18 & 75.3 & 176 & 65 \\
\hline $\mathrm{C}_{2} \mathrm{mim} \mathrm{HSO}_{4}$ & 160 & 30 & 1.36 & 130 & $<-30$ & 46.7 & 2.1 & 2.3 \\
\hline $\mathrm{C}_{2} \mathrm{mim} \mathrm{C}_{2} \mathrm{H}_{5} \mathrm{SO}_{4}$ & 80 & 13 & 1.24 & 142 & $<-30$ & 45.1 & 6.05 & 3.2 \\
\hline $\mathrm{C}_{2} \operatorname{mim} \mathrm{SCN}$ & 15 & 7 & 1.11 & 212 & -50 & 37.9 & 2.43 & 1.47 \\
\hline $\mathrm{C}_{2} \mathrm{mim} \mathrm{CH}_{3} \mathrm{COO}$ & 75 & 13 & 1.10 & 141 & -20 & 45.4 & 0.54 & 3.5 \\
\hline
\end{tabular}

Table 2: Thermo-physical properties and corrosion rate data for four DESs, four imidazolium based ionic liquids and a mineral base oil.

Most of the DESs and imidazolium based ionic liquids also have improved freezing points compared to the base oil suggesting improved performance at lower temperatures. The urea based eutectic with choline chloride has too high a freezing point and coupled with the propensity for urea to break down to form ammonia at high temperatures would probably make it unsuitable for general use. The glycol based liquids are, however better at both high 
and low temperatures and have high $\boldsymbol{V I}$ values. The benign nature, particularly of glycerol, makes this eutectic an interesting candidate for a marine lubricant because it is totally miscible with water and would disperse if discharged at sea. Since both components are extremely benign they pose negligible threat to aquatic life. The four imidazolium-based ionic liquids also show high viscosity indexes and thermal properties. They are also miscible with water and $\mathrm{C}_{2}$ mim has been shown to have relatively low toxicity although anions such as SCN are clearly undesirable. ${ }^{14}$

Corrosion Rate Data: Viable lubricants must also be non-corrosive which is why mineral oils have been widely used. While viscosity data exists for most ionic liquids very little data exists on their compatibility with metals. ${ }^{15}$ Table 2 shows the corrosion rates for mild steel in 4 DESs and four ionic liquids. The corrosion was studied using both linear sweep voltammetry and electrochemical impedance spectroscopy (EIS) and Table 2 shows that both had similar trends and magnitudes. It is well known that chloride based media can significantly enhance the corrosion rate in aqueous solution as it breaks down passive films. ${ }^{16}$ As such it would seem logical that it should be avoided for lubricant applications. Table 2 shows the initial corrosion rates as determined using Tafel slopes from slow-rate linear sweep voltammetry. These are extremely low for Ethaline, Glyceline and Reline but extremely high for Oxaline. The origin of this difference could be due to the presence of an insulating film on the metal surface or the kinetics of either the anodic or cathodic processes. The Tafel slope shows that in Ethaline, Reline and Glyceline the cathodic slope is shallow suggesting that the cathodic process is rate limiting. In these liquids the cathodic process is the reduction of oxygen i.e.

$$
\mathrm{O}_{2}+2 \mathrm{H}_{2} \mathrm{O}+4 \mathrm{e}^{-} \leftrightarrow 4 \mathrm{OH}^{-}
$$

The very high chloride concentration will decrease the activity of water as it is highly hydrogen bonded. In the oxalic acid based eutectic however the cathodic process is extremely fast as it is just the reduction of protons to form hydrogen gas allowing much faster corrosion. Interestingly in this liquid bright yellow sheets of iron oxalate form parallel to the metal surface until all the metal is dissolved, which effectively filled the sample tube by the end of the experiment.

The very unusual aspect of DESs is their propensity to prevent corrosion even when the liquid is doctored with an electrolyte solution. Figure 1 shows that when 1 wt $\%$ water containing $3 \mathrm{wt} \% \mathrm{NaCl}$ (a mimic of sea water) is added to the mineral oil significant 
corrosion is observed of the mild steel immersed in the liquid after 2 weeks. Clearly the aqueous phase partitions to the steel surface where corrosion is caused by the relatively high chloride concentration. Figure 1 shows an analogous experiment where choline chloride is added to the aqueous solution in place of sodium chloride and it can be seen that corrosion occurs but to a lesser extent. This surprisingly shows that there is a cation effect to the corrosion mechanism which is not fully understood at present but may be related to the relative solubility of the corrosion products. Figure 1 also shows corrosive effect of Ethaline and Glyceline to which the same aqueous electrolytes were added in the same amounts. No visible signs of corrosion were detected on mild steel even after 6 months whereas in wet base oil corrosion was clearly visible within two days. This unusual observation shows that, counter to perceived wisdom, mild steel does not show signs of corrosion in a high chloride medium (approximately $5 \mathrm{~mol} \mathrm{dm}^{-3}$ ).

Table 3 shows the initial corrosion rate for iron, nickel and aluminium in four DESs as a function of water content. It can be seen that the glycol based liquids are relatively insensitive to the addition of water, whereas the urea and oxalic acid significantly increase the rate of corrosion for iron compared to an aqueous solution. Surprisingly aluminium only shows very slow corrosion when water is added even with a high chloride concentration presumably due to oxalate being able to passivate the metal surface. The formation of a passivating film can clearly be observed using a.c. impedance spectroscopy.

The low corrosion rate of common metals with glycol-based DESs even with significant water content suggests that they may be useful media as base lubricants particularly for marine applications.

Electrochemical a.c. impedance spectroscopy shows that while slow corrosion occurs initially and a passivating layer appears to form for a range of metals including $\mathrm{Ni}$ and $\mathrm{Al}$. Comparing the corrosion rates for the imidazolium based ionic liquids with those for the DESs and base oil shown in Table 2 it can be seen that the corrosion rate of mild steel in the most hydrophobic anion, ethylsulfate, is considerably higher than either hydrogen sulfate or SCN presumably due to its inability to bind traces of water. The acetate anion showed the lowest rate of corrosion. It appears to hold that ionic fluids with more Lewis basic anions tend to demonstrate enhanced corrosion resistance. 


\begin{tabular}{|l|c|c|c|c|}
\hline \multicolumn{5}{|c|}{ Corrosion rate of Fe $(\mu \mathrm{m} /$ Year $)$} \\
\hline & Glyceline & Ethaline & Reline & Oxaline \\
\hline Pure DES & 0.40 & 1.98 & 2.503 & 176.4 \\
\hline $1 \%$ water & 0.74 & 2.51 & 3.220 & 169.1 \\
\hline $2 \%$ water & 0.86 & 3.25 & 9.688 & 110.5 \\
\hline $5 \%$ water & 1.72 & 2.68 & 12.30 & 82.78 \\
\hline $10 \%$ water & 2.95 & 4.35 & 17.550 & 206.2 \\
\hline $0.1 \mathrm{M}$ aqueous $\mathrm{KNO}_{3}$ & 7.32 & 7.32 & 7.32 & 7.32 \\
\hline \multicolumn{5}{|c|}{ Corrosion rate of Al $(\mu \mathrm{m} /$ Year $)$} \\
\hline Pure DES & 0.68 & 1.02 & 1.99 & 3.82 \\
\hline $1 \%$ water & 1.10 & 1.55 & 1.37 & 2.30 \\
\hline $2 \%$ water & 1.12 & 1.78 & 1.36 & 2.05 \\
\hline $5 \%$ water & 1.19 & 1.82 & 1.40 & 2.40 \\
\hline $10 \%$ water & 1.41 & 1.94 & 1.55 & 2.11 \\
\hline $0.1 \mathrm{M}$ aqueous $\mathrm{KNO}_{3}$ & 5.86 & 5.86 & 5.86 & 5.86 \\
\hline \multicolumn{5}{|c|}{ Corrosion rate of Ni $(\mu \mathrm{m} /$ Year $)$} \\
\hline Pure DES & 0.09 & 4.18 & 1.59 & 25.9 \\
\hline $1 \%$ water & 0.23 & 6.79 & 1.60 & 63.1 \\
\hline $2 \%$ water & 0.51 & 7.96 & 2.24 & 58.7 \\
\hline $5 \%$ water & 1.14 & 9.62 & 4.64 & 90.0 \\
\hline $10 \%$ water & 1.53 & 7.30 & 8.79 & 126.8 \\
\hline $0.1 \mathrm{M}$ aqueous $\mathrm{KNO}_{3}$ & 8.05 & 8.05 & 8.05 & 8.05 \\
\hline \multicolumn{5}{|c|}{} \\
\hline
\end{tabular}

Table 3: Corrosion rates of Fe, Al and Ni in four DESs as a function of water content determined using linear sweep voltammetry and Tafel slope analysis.

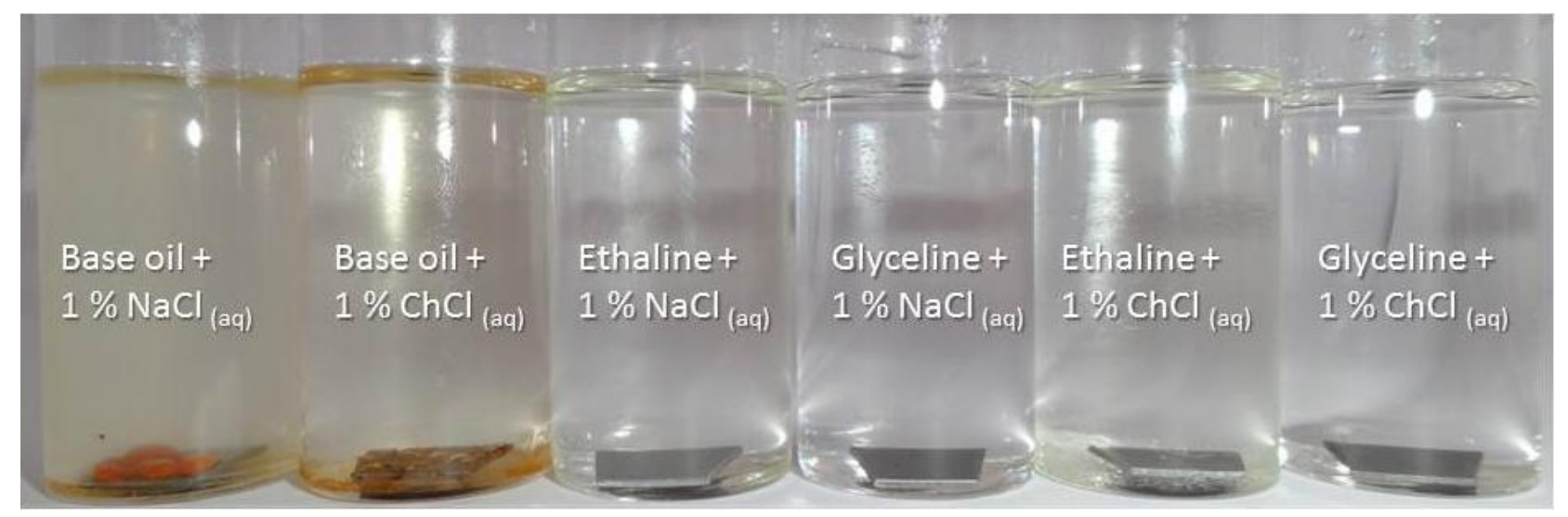

Figure 1: Corrosion behaviour of mild steel after 2 weeks immersed in DESs and mineral base oil containing $1 \% \mathrm{NaCl}_{(a q)}$ and $1 \% \mathrm{ChCl}_{(a q)}$.

Wear Resistance: We have previously shown that adding quaternary ammonium electrolytes to glycerol can significantly reduce the friction coefficient which shows that the 
ionic component has an interfacial preference which allows it to interact with the metal and produce an interfacial barrier. ${ }^{12}$ Studies in pure imidazolium based liquids have shown that the metal liquid interface is highly structured with most probably alternating layers of cations and anions. ${ }^{17,18}$ Friction modifying additives which decrease the friction coefficients for base oils tend to be relatively polar and include fatty acid derivatives such as glycerol monooleate ${ }^{2}$ or the correspond oleylamide. The polar functional groups are thought to chemisorb onto the metal surface through the mechanical wear of one surface with another. An alternative additive is an organometallic compound such as zinc dialkyldithio phosphate which forms a complex insoluble film of 10-200 nm thickness this acts as an anti-wear layer. ${ }^{2}$ Previous studies have shown that glycolate films form from the electrooxidation of iron and nickel in DESs. These tend to have a characteristic a.c. impedance spectra ${ }^{19}$ which are similar in magnitude to those observed on prolonged contact with the DESs and iron electrodes.

\begin{tabular}{|c|c|c|c|c|c|c|}
\hline \multirow{3}{*}{ ILs } & \multirow[b]{2}{*}{ Properties } & \multicolumn{5}{|c|}{ Substrate Metals against stainless steel } \\
\hline & & $\mathrm{Al}$ & Bronze & $\mathrm{Cu}$ & $\begin{array}{l}\text { Mild } \\
\text { Steel }\end{array}$ & Stainless Steel \\
\hline & $\begin{array}{l}\text { Surface Activity } \\
\left(\mathrm{mJ} / \mathrm{m}^{2}\right)\end{array}$ & 867 & 1534 & 1650 & 2150 & 2075 \\
\hline \multirow{2}{*}{ Ethaline } & Contact angle & 66.1 & 72.7 & 88.3 & 70.9 & 82.4 \\
\hline & $\mu_{k}$ & 0.15 & 0.58 & 0.59 & 0.30 & 0.37 \\
\hline \multirow{2}{*}{ Glyceline } & Contact angle & 79.5 & 77.5 & 84.7 & 92.2 & 86.3 \\
\hline & $\mu_{k}$ & 0.55 & 0.40 & 0.45 & 0.28 & 0.38 \\
\hline \multirow{2}{*}{ Reline } & Contact angle & 74.4 & 93.2 & 94.9 & 90.5 & 90.7 \\
\hline & $\mu_{k}$ & 0.31 & 0.26 & 0.21 & 0.32 & 0.28 \\
\hline \multirow{2}{*}{ Oxaline } & Contact angle & 76.52 & 30.4 & 28.7 & 40.8 & 51.7 \\
\hline & $\mu_{k}$ & 0.25 & 0.29 & 0.18 & 0.38 & 0.30 \\
\hline \multirow{2}{*}{ Emim SCN } & Contact angle & 61.4 & 50.3 & 64.3 & 60.4 & 68.7 \\
\hline & $\mu_{k}$ & 0.29 & 0.33 & 0.23 & 0.47 & 0.28 \\
\hline \multirow{2}{*}{$\mathrm{Emim} \mathrm{HSO}_{4}$} & Contact angle & 85.2 & 77.6 & 58.3 & 57.2 & 71.2 \\
\hline & $\mu_{k}$ & 0.30 & 0.42 & 0.20 & 0.48 & 0.23 \\
\hline \multirow{2}{*}{$\mathrm{Emim} \mathrm{EtSO}_{4}$} & Contact angle & 52.0 & 70.9 & 62.4 & 56.4 & 62.4 \\
\hline & $\mu_{k}$ & & 0.43 & 0.50 & 0.30 & 0.22 \\
\hline \multirow{2}{*}{ Emim OAc } & Contact angle & 67.9 & 57.3 & 62.2 & 54.9 & 69.2 \\
\hline & $\mu_{k}$ & & 0.45 & 0.50 & 0.28 & 0.23 \\
\hline \multirow{2}{*}{ Base oil } & Contact angle & 7.6 & 18.0 & 12.8 & 11.7 & 11.3 \\
\hline & $\mu_{k}$ & 0.12 & 0.23 & 0.37 & 0.40 & 0.45 \\
\hline
\end{tabular}

Table 4: Coefficient of kinetic friction, $\mu_{k}$, and contact angles of various water miscible ionic liquids and DESs for several metal contacts with mild steel. Surface activity values were calculated for alloys using linear combinations of the values of the individual components

Table 4 shows that the DESs show lower friction coefficients than base oil with stainless steel, but slightly higher values for aluminium couples. This is thought to result from the 
relative abilities of the liquids to wet the different surfaces. This concept was tested by measuring the contact angle of the metals with different DESs. Clearly mineral oils with their low surface tension and low contact angles should be able to better wet surfaces but it depends to some extent on the nature of the surface. An indicator of the hydrophilicity of the surface activity of the liquid metal and Table 4 shows that aluminium has a low surface energy whereas iron based alloys have a high surface activity. It seems logical therefore that ionic liquids with high surface tensions and high contact angles should show improved friction coefficients over base oils with iron based alloys whereas the reverse is the case for aluminium and bronze alloys.

\section{Conclusion}

This study has shown that DESs, particularly those based on glycols together with choline chloride have the correct lubricity, toxicity and corrosivity to be viable options for base lubricants. Their ability to be miscible with water in all proportions and to suppress corrosion even when slightly wet means that they could be of particular use for marine lubricants. Friction coefficient measurements suggest that they have improved tribological properties with respect to mineral oils for iron-based alloys which are clearly the important materials for lubrication whereas the converse is the case for more hydrophobic surfaces such as aluminium.

\section{Acknowledgements}

The authors would like to thank the Higher Committee for Education Development in Iraq and Salahaddin University for a studentship (E.I. Ahmed). 


\section{References}

Z. Pawlak, Tribochemistry of Lubricating Oils, Elsevier Science, 2003

2 L. R. Rudnick, Lubricant Additives: Chemistry and Applications, 2 Ed. CRC Press, Boca Raton, USA, 2009.

3 R. M. Mortier, M. F. Fox and S. T. Orszulik, Chemistry and Technology of Lubricants $3^{\text {rd }}$ Ed, Springer, Dordrecht, 2010.

4 A. Adhvaryu, B. K. Sharma, H. S. Hwang, S. Z. Erhan and J. M. Perez, Ind. Eng. Chem. Res., 2006, 45, 928-933.

5 B. K. Sharma, J. M. Perez and S. Z. Erhan, Energy Fuel, 2007, 21, 2408-2414.

6 W. H. Millett, Ind. Eng. Chem., 1950, 42, 2436-2441.

7 A. E. Somers, P. C. Howlett, D. R. MacFarlane and M. Forsyth, Lubricants, 2013, 1, 3-21

8 F. Zhou, Y. Liang and W. Liu, Chem. Soc. Rev., 2009, 38, 2590-2599.

9 A. P. Abbott, G. Capper, D. L. Davies, R. K. Rasheed and V. Tambyrajah, Chem Commun, 2003, 70-71.

10 A. P. Abbott, D. Boothby, G. Capper, D. L. Davies, R. Rasheed and V. Tambyrajah $J$. Am. Chem. Soc. 2004, 126, 9142.

11 ASTM, "Standard Practice for Calculating Viscosity Index From Kinematic Viscosity at 40 and $100^{\circ}$ C" ASTM Standard D 2770, Annual Book of ASTM Standards, American Society for Testing Materials, ASTM International, West Conshohocken, PA., 2004.

12 S. D. A. Lawes, S. V. Hainsworth, P. Blake, K. S. Ryder and A. P. Abbott, Tribol. Lett, 2010, 37, 103-110.

13 G. L. Burrell, N. F. Dunlop and F. Separovic, Soft Mat., 2010,6, 2080-2086

14 C. Pretti, C. Chiappe, D. Pieraccini, M. Gregori, F. Abramo, G. Monni and L. Intorre Green Chem., 2006, 8, 238-240.

15 Y-C. Wang, T-C. Lee, J-Y. Lin, J-K. Chang, C-M. Tseng. Corr. Sci. 2014, 78, 81-88

16 R. W. Revie, Corrosion and Corrosion Control, Wiley, New York, 2008.

17 R. Atkin, S.Z. El Abedin, R. L. Hayes, L. H. S. Gasparotto, N. Borisenko and F. Endres, J. Phys. Chem. C, 2009, 113 13266-13272.

18 R. L. Hayes, N. Borisenko, M. K.Tam, P. C. Howlett, F. Endres, R. Atkin, J. Phys. Chem. $C, 2011,115,6855-6863$.

19 A. P. Abbott, G. Capper, K. J. McKenzie and K. S. Ryder, Electrochim. Acta 2006, 51, 4420-4425. 